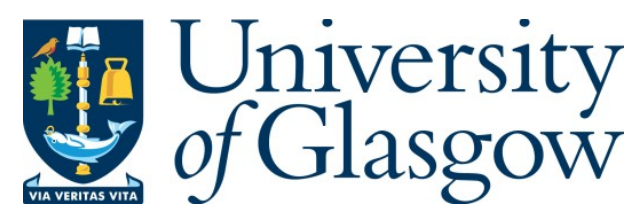

Bowness, J. (2020) Risk accepters and problem solvers: managing risk in the Masters Highland Games. European Journal for Sport and Society, 17(1), pp. 66-81.

(doi: 10.1080/16138171.2019.1706250)

This is the Author Accepted Manuscript.

There may be differences between this version and the published version. You are advised to consult the publisher's version if you wish to cite from it.

https://eprints.gla.ac.uk/190826/

Deposited on: 23 July 2019

Enlighten - Research publications by members of the University of Glasgow http://eprints.gla.ac.uk 


\title{
Risk Accepters and Problem Solvers: Managing Risk in the Masters Highland Games
}

\begin{abstract}
Narratives of ageing are often negative, focusing on later life as a period defined by biological decline. A growing population of older adults (Masters athletes) participating in sport challenge these assumptions. Existing research demonstrates how Masters athletes transcend and challenge dominant discourses of ageing and resist enfeeblement. To do so requires a negotiation with risk, pain and injury. Examining these processes in younger athletes developed within the sociology of sport during the 1990's. This literature explored risk-taking sub-cultures across different sports and between genders. Yet an analysis of how older athletes manage risk has hitherto not taken place. In order to expand this corpus of work to Masters athletes, this article provides a case study of the Masters Highland Games. Drawing upon in-depth interviews with 19 athletes aged between 40 and 75, two ideal types that describe approaches to risk taking are proposed. Informed by the ideas of Giddens, these ideal types will demonstrate the variety of ways that resistance relates to risk, pain and injury. This case study demonstrates that some Masters athletes share traits identified in research with younger athletes, such as the acceptance of their practice being inherently risky and the act of normalising pain. However, most Masters athletes exhibit a more problem solving approach that adopts various strategies that manage the risks of ageing.
\end{abstract}

Keywords: risk, successful ageing, ageism, sport, Highland Games,

\section{Author Details \\ Dr James Bowness \\ University of Glasgow. \\ James.bowness@glasgow.ac.uk}

\section{Introduction}

In an albeit uneven fashion, population ageing is occurring across the globe (Davies and James, 2016). In the West a growing number of people are continuing, restarting or beginning a sports career in later life (Baker, Fraser-Thomas, Dionigi, \& Horton, 2010). Those competing in organised sport are referred to as Masters athletes. These individuals partake in practices which contrast with common connotations of ageing. Discourses of the ageing process are 
overwhelmingly negative (Powell \& Biggs, 2003), frequently portraying ageing as a march towards frailty and bodily dependence. This focus on embodied ageing is perpetrated and reproduced through the medicalisation of bodies (Estes \& Binney, 1989; Tulle, 2008a). For example, the Academy of Medical Science $(2009$, p5) define ageing as a 'deleterious side effect of biological process' and a 'gradual accumulation of a complex, diverse and tissue-specific array of faults'. Here, ageing is simply deterioration. Currently, biomedical discourses of ageing hold a hegemonic position, providing a challenging environment for those who wish to pursue sport in later life (Palmer, Tulle, \& Bowness, 2018). Masters sport presents a social activity that situates the ageing body in physical practices that are antithetical to established narratives of ageing as decline. Those older adults who remain physically active are often celebrated as 'successful agers' (Rowe and Kahn, 1987; Geard, Reaburn, Rebar, \& Dionigi, 2017) or as 'heroes of ageing' (Featherstone \& Hepworth, 1995b), who resist stereotypes of ageing (Tulle, 2008b; Phoenix and Smith, 2011; Pike, 2011a).

The process of resisting a 'discourse of decline' (Gullette, 1997) requires a reformulation of what ageing is and can be. These 'successful agers' must construct a counter story of their ageing; to be freed from the shackles of a narrative of decline (Phoenix and Smith, 2011). Masters athletes may also use what Featherstone and Hepworth (1995a) theorised as the 'mask of ageing'; a dividing of the ageing body from the ageless self in order to justify what are seen to be agedeviant behaviours (Dionigi, 2002; Tulle, 2008a). The often cited phrase 'I don't feel old' characterises the 'mask of ageing' (Thompson, 1992). The perceived evasion of ageing reproduces a form of ageism that suggests normative ageing is expected to be negative (Pike, 2011a).

Other unintended consequences of Masters sport have also been identified. The use of counter narratives of ageing can inadvertently reproduce ageism (Dionigi, 2015) and a healthism that may also contribute to a 'moral panic' around those older adults who do not partake in sport or physical activity (Pike, 2011b, Pfister, 2012). Such ethical concerns have led others to suggest that the performance of physical activity for the sake of successful ageing is inherently a 'moral practice' (Dallaire, Lemyre, Krewski, \& Gibbs, 2012). These practices exemplify the hegemonic narrative of being a 'responsible citizen' (Brown and Baker, 2012), with individuals taking control of their ageing via physical practices that avoid or delay morbidity (Dankel, Loenneke, \& Loprinzi, 2017). This is consistent with those who have argued that contemporary neoliberal society aims to produce self-governing citizens that engage with appropriate experts to limit the risk of negative health outcomes (Bunton and Burrows, 1995; Bernstein, 2001, Brown and Baker, 2012).

Nevertheless, narratives that resist ageing have led to modes of ageing embodiment that were previously unknown. In locating this turn to health promotion and successful ageing, we can consider these individuals as living an 'emergent form of life' (Rose, 2007, p90). A relatively new mode of being which has created new meanings of later life. These new life forms have arguably altered the nature of sporting participation more broadly. In the early 1980's, Featherstone and Hepworth (1982) suggested that running for the sake of running had been lost in an all-encompassing narrative of physical activity for health. In contrast, a variety of elite sporting sub-cultures prioritise the logics of sport over any concern for health (Theberge, 2007; 
Sinden, 2010). But do Masters athletes frame their sport as a health practice, or do they disregard health in the same way as younger athletes of Albert (1999), Waldron and Crane (2005) and Sinden (2010)? To examine the Masters phenomenon, we must contrast their experiences to those younger athletes that have been the focus of existing scholarship on risk, pain and injury in sport.

\section{Sport and Risk}

Examinations of risk in sporting contexts have focused on the perceptions, experiences and understandings of pain and injury (Young, 2004; Loland, Skirstad, \& Waddington, 2006). The negative outcomes of risk taking in sport are often physical injury and subsequent pain. The ways in which athletes understand and manage pain and injury has been examined across a variety of sporting fields, including cycling (Albert, 1999), professional football (Roderick, Waddington, \& Parker, 2000), rowing (Pike, 2005) and running (Bale, 2006). Emerging from these case studies is a consensus of sport as a plurality of activities that tends more towards a 'culture of risk' (Nixon, 1992) rather than a 'culture of precaution' (Safai, 2003). It is also apparent that the riskiness of various activities is concealed by normalising practices that make up the logic of specific sporting sub-cultures (Hughes and Coakley, 1991; Curry and Strauss, 1994). The normalisation of risks means that many athletes fail to acknowledge particular risks that are easily identified by those outside of that specific sub-culture (Monaghan, 2001). Sport can also be seen as a set of practices that reformulate a relation between an athlete and pain. Learning to embrace pain is often an inherent aspect of sporting participation (Sabo, 2007). Taking risks and embracing pain may be required to develop careers (Lupton, 2013), maintain athletic identities (Sabo, 2004; Pike, 2007) or aid inclusion within a sporting group (Donnelly, 2004).

Alongside the wider growth of a critical feminist perspective to the study of men in sport (Messner, \& Sabo, 1990; McKay, Messner, \& Sabo, 2000), the 1990's saw a flurry of publications that examined masculinity and sporting injury (Messner, 1992; Young, 1993; Young, White, \& McTeer, 1994, Nixon, 1996). Much of this literature proposed that men strive towards a legitimate or 'hegemonic masculinity' (Connell, 2005, p77), one that involves risk taking, ignoring pain, downplaying injury and suppressing emotional weakness. Until the early 2000's research on risk, pain and injury in sport was predominantly directed towards male sporting sub-cultures (Charlesworth, 2004). A growing body of female case studies demonstrate the similarities between men and women in relation to risk, pain and injury (Young and White, 1995; Charlesworth, 2004; Sabo, 2004; Charlesworth, \& Young, 2006).

Aside from gender, research has also explored the cultures of risk taking across different levels of sport. A field that initially focused on professional and collegiate sport (Liston, Reacher, Smith, \& Waddington, 2006) has been expanded through the exploration of more recreational or mass forms of sport. For example, Liston et al., (2006) found that amateur Rugby players also approached risk, pain and injury in ways that had been found in professional sport settings. These approaches appear to extend far beyond professional or elite sporting participation (Brymer, 2010; Liston, McDowell, Malcolm, Scott-Bell, \& Waddington, 2016; Malcolm and 
Pullen, 2019), and may even be incorporated by those who use sport as a form of preventative medicine (Pullen and Malcolm, 2018).

This subject area has now established an understanding of why athletes take risks, how risks are normalised and how risk is understood by young men and women. As younger people make up the majority of sporting participants (Eime, Harvey, Charity, \& Payne, 2016), it is not surprising that older athletes are absent in this literature. Age itself is not entirely missing, but its rare inclusion is often to correlate immaturity with risk taking behaviours (Donnelly, 2004; Sabo, 2004). For example, Donnelly $(2004$, p38) speculates that risk-taking behaviours, not merely in sport, are 'deliberately' acted out between the ages of 16-24, before the 'serious business of work, marriage and parenting' begins. Others have called for research to examine the impact of youthful injuries on later life sporting participation (Young, \&White, 2000). Such work assumes a difference in later life associated around the 'costs not anticipated during one's youth, when the body seemed vibrant and invulnerable' (Young, \& White, 2000, p125). Ageing, therefore, has not been entirely missing, but a focus on ageing men and women in sport is missing.

This study aims to extend literature on risk in sport to Masters athletes; adding a concern with ageing to a body of work which has already explored a range of sub-cultural differences. As Masters athletes are not professional sports participants, this work also adds to a growing corpus of work that explores non-elite/professional sporting contexts. This paper will therefore explore the following questions: how do Masters athletes manage risks in their sport? Do Master athletes manage risk, pain and injury in similar ways to younger athletes, or does the ageing process create different approaches to risk taking in sport? Using a case study of Master athletes in the Highland Games, this contribution demonstrates how Masters athletes negotiate competing discourses about ageing, sport and the body. An analysis of risk through the work of Anthony Giddens will detail the differences and similarities between the young athletes of existing research and the Master athletes of the Highland Games.

\section{Giddens, Risk and Ageing}

The work of Anthony Giddens (1991a; 1991b, 1992, 1999) falls under what some have called reflexive modernisation (Beck, Giddens, \& Lash, 1994). Reflexive modernists suggest that contemporary social life is characterised by an increased tendency to evaluate, reflect and manage the potential risks created and perceived by modernity. For Giddens (1991a, p7), modernity is a 'double edged phenomenon' that has both created opportunities for the good life, whilst also drawing attention to dangers that did not existed before. Growing knowledge of possibilities and problems has also revealed the limits of expertise (Giddens, 1991b). The medicalisation of disease offers new answers to human problems, but it also generates new questions around the limitations of biomedical knowledge. The declining role of religion and the secularisation of modern social life, imply that faith no longer offers totalising answers to existential questions (Giddens, 1991a). This can be understood as a risk shift, a movement away from uncontrollable fate and towards a new control of the future. This new found agency leads Giddens (1991a) to suggest that new platforms for social change now exist. However, the rapid 
social change associated with late modernity has produced widespread ontological insecurity (Giddens, 1991b), whereby a sense of continuity in people's everyday lives is challenged.

The emergence of a 'life politics', focusing on the politics of choice, means that increasing numbers of people are travelling social trajectories that few have travelled before. Giddens (1991b) refers to these individuals as risk pioneers. These pioneers exist in the gaps of expertise; areas where knowledge is either absent, incomplete or contradictory. In these enclaves, individuals choose between two forms of risk that Giddens (1991a, 1991b) roughly differentiates as traditional and modern. These can also be divided into risk as adventure or risk as insurance (Giddens, 1991b). In exploring the etymology of the word, Giddens (1999) finds the first use of 'risk' in the $16^{\text {th }}$ and $17^{\text {th }}$ centuries. Its entrance into English comes via Spanish or Portuguese and was used by Western explorers in reference to 'sailing into uncharted waters' (Giddens, 1999, p21). Risk in this sense can be linked to a translation from Portuguese that means 'to dare' (Giddens, 1999).

In contrast, Giddens (1999) also discusses a formulation of risk as insurance. Here risk is understood as hazardous; something that an individual wish to avoid. Practical steps such as health insurance shift the risk against potentially negative health outcomes and can be seen as an attempt to regulate the future (Giddens, 1999, p6). One concept linked to this form of risk is the precautionary principle, an idea most readily associated with environmental issues. This principle suggests that action to avoid negative outcomes 'should be taken even though there is insecure scientific evidence about them' (Giddens, 1999, p32).

The use of Giddens within sport sociology is limited (Horne, \& Jary, 2004), but applying his ideas to Masters athletes is warranted on various levels. Masters athletes can be viewed as risk pioneers and individuals that are living within on-going social change around who participates in sport. An emerging health imperative towards the end of the $20^{\text {th }}$ century was one such social change that rationalised exercise for the sake of self-preservation (Lupton, 1995). Participation in this sense appears to be an example of risk as insurance. This lies in contrast to the ignorance of risks that athletes may endorse in order to further a sporting careers (Lupton, 2013). This article will therefore analyse the risk approaches of Master athletes, aided by the theoretical works of Giddens. A case study of the Masters Highland Games will detail two ideal types that I have named problem solvers and risk accepters.

\section{Masters Highland Games Case Study}

The Highland Games are popular community events which combines a variety of cultural practices within a single event space. Originally from Scotland, events now occur across many nations that contain a significant Celtic diasporic population. The nations of Australia, Canada and the US all have Highland Games that were borne out of Caledonian societies and diaspora driven community events (Jarvie, 2005). The centrepiece of the Games is the heavy athletics, involving athletes throwing heavy objects as high or far as possible. The most famous heavy athletics event is the caber toss, which involves the flipping of a long wooden pole weighing $100-180 \mathrm{lbs}(45-81 \mathrm{~kg})$. These challenge both muscular strength and postural stability; two risk factors relating to injury to the lower extremity (Murphy, Connolly, \& Beynnon, 2003). The 
terrain is nearly always on grass; a surface that can be wet, slippy and damaged from previous throws. These conditions pose a further risk of physical injury (Dragoo and Braun, 2010).

Annual World Championship competition for Masters began in 2001. The Masters World Championships have been held in the US, Canada, Scotland, Iceland and Germany. Masters Highland Games competition begins at the age of 40. The heavy athletics at the Masters World Championship follows the North American format which involves 8 events spread over 3 days. This case study is based on data collected at the 2014 World Masters Championships in Inverness, Scotland. Research participants ( $n=19)$ came from the USA (16), Canada (1), Germany (1) and England (1). All athletes were white. The age of participants in this study ranged from $40-75$ and had a mean age of 55. Most athletes in this sample were aged between 40 and $50(n=11)$, reproducing the representative dominance of this age group at the World Championships. The World Championships were also predominantly participated in by men. This was reproduced in this sample of athletes, whereby 13 men and 6 women were interviewed. In terms of social class, no formal measure was taken, but most participants were college educated and had secure work. There was one athlete who had attended the games after her local colleagues had crowdfunded her trip. Furthermore, athletes' trips to Inverness often spawned into a prolonged family vacation which requires significant economic capital. In this sense, the sample reproduced the dominance of middle-class athletes found elsewhere within Masters sport (Dionigi, 2015).

Participants were initially approached through their community Facebook group. This led to the arrangement of meetings at the 2014 Masters World Championships event in Inverness. Later snowball sampling was used to access other athletes. This took place in person at the event and later online. Data collection therefore took place in two waves and involved interviews both in person and online. Interviews with 13 athletes took place at the event itself. E-mail interviews with a further 6 athletes occurred in early 2015. To gather, consolidate and clarify data, email interviews were used with 2 athletes that had been interviewed in person during the World Championships.

Interviews, the primary mode of data collection, used a mixture of ethnographic, life history and phenomenological approaches. Ethnographic questions aimed to examine the culture of the Masters Highland Games community. Life history questions explored earlier experiences of sporting participation and aimed to shed light on how individuals became Masters athletes. Questions regarding the lived experience of ageing used a phenomenological perspective that led to the interpretation of the subjective embodied experiences of these Masters athletes. The embodied experiences of training and competing emanated from a series of questions on pain, injury, ageing and risk. Such an approach highlighted the bodily regimes used to delay or manage the ageing process as well as demonstrating a range of understandings of what ageing meant and what risks challenged the ageing body.

Data was transcribed verbatim and analysed using an interpretive phenomenological approach (Smith, Flowers, \& Larkin, 2009) to uncover the underlying mechanisms in how individuals construct meaning. Data analysis of the IPA ilk began by re-reading transcripts in order to become immersed in the data. To comprehend individual experience, initial notetaking took 
place without a formal coding framework (Smith et al., 2009). The coding of data eventually led to the creation of emergent themes. A variety of approaches to managing risk, pain and injury was one of three bigger emergent themes. These three themes were connected by a concern with embodiment and ageing. In moving from the minutia of individual experience to broader intersubjective themes, data analysis developed from individual interpretation to the researcher's broader interpretation. This sense making process has been named the 'double hermeneutic' (Smith et al., 2009, p3).

Emerging from the data were two approaches to risk that were contextualised in relation to the ageing process. Both approaches resist the hegemonic discourse of decline that frames older adults as biologically deteriorating (Tulle, 2008a). Two ideal types labelled 'risk accepters' and 'problem solvers' provide a heuristic tool to understand the complexity surrounding how Masters manage risk.

\section{The Risk Accepter-Problem Solver Ideal Types}

The use of ideal types here draws upon the work of Weber (1978, p21), who advocated their use for 'heuristic purposes'. An ideal type is a conceptual abstraction that is used to explain a social phenomenon, in this case the ways in which ageing is resisted. The ideal types used here are the product of an inductive analysis of empirical work. The theory of Gidden's has been used to underpin these ideal types. The two ideal types created here have been named risk accepters and problem solvers. For the purposes of illumination, I will refer to five athletes, including one woman (52) and four men (46-59). These cases should be taken as representative of traits shared within the wider sample, including those athletes between 60 and 75 . I will begin with the risk accepter before describing the contrasting ideal type of the problem solver.

\section{Risk Accepters}

The risk accepter acknowledges that there are a variety of risks to the Masters career, yet participation continues with no precautionary measures taken. The training regimes used to prepare for the Games reproduce what was learnt earlier in a career, when the athlete was younger. A belief in positive thinking, commitment and confidence are drawn upon to mitigate against the hazards of sporting competition. Continuing to participate in the Games, whilst carrying an injury was typical of the risk accepter. An example comes from Ethan (59, M):

My injuries were something I had to deal with all season long so throwing in Inverness wasn't a concern because I had been pushing the last half of my season to test them. I remember throwing in Inverness like it was yesterday. I was calm. I had just a little shoulder pain but pulling on a 130lb-19ft Caber does that anyway. My sport being risky? Of course.

Here Ethan acknowledges the risks inherent to his sport. Yet he also demonstrates a commitment to pushing on through pain and voices a lack of concern around playing hurt. It became obvious that others would not attempt to intervene in Ethan's participation. His wife was concerned with 
his pain and injuries, but Ethan said she never tried to stop him from competing. A similar environment existed with Ethan's fellow competitors:

We do monitor each other, help ice, apply sports cream, wrap, massage spasms but never has any of us tried to discourage another from competing.

The existence of pain was therefore normalised and to some extent expected by the group. Athletes would help in the event of an injury, but these were not precautionary measures and no fellow athlete would tell another athlete not to continue competing. The relative autonomy of Master athletes in preparing for sport also meant that athletes often didn't have coaches, social actors who influence approaches to pain normalisation and risk taking (Nixon, 1994; Mayer, \& Thiel, 2018). Resisting ageing in this manner reproduces some of the traits associated with a younger risk-accepting masculinity that trivialises pain and potential injury (Messner, 1992; Young, 1993). What was also interesting was how Ethan justified his embrace of risky physical practices:

It might seem strange to someone on the outside looking in and noticing my age. When they ask me why? Why risk injury? I always think of a quote that I heard once. It was from a mountain climber, George Mallory but I'm not positive. When asked about his climb and possible death he responded I didn't climb this mountain to die but to live. That's how I feel when I step onto the field and our side of the fence with the family, brothers from other mothers. I do it to LIVE. (his emphasis)

This understanding of risk positions risk-taking in a binary between living and merely existing. To accept the risk and to live is to resist the physical inactivity that is normative of others of a similar age and inherent in the discourse of decline (Gullette, 1997). This narrative tool relies upon the reproduction of ageist discourses that emphasise social and physical disengagement with age (Powell, \& Biggs, 2003, Dionigi 2015). Participation using this approach places a will to 'live' as an appropriate reward for risk taking, a framing of risk taking that is potentially different to those in younger athletes (Young et al., 1994; Young, \& White, 2000). Existing research understands that risks may be taken for inclusion into a group or for the protection and expansion of a career or identity, but these may be qualitatively different from an existential question that relates to living or existing. What is similar to younger athletes is the way Ethan described his desire to maintain an identity and experience:

The draw for me is the look on people's faces which leads to one giant exhale when a huge Caber gets turned. The slower the better. I look at it this way. I'm 59 and in not too bad of shape, who works the line at Ford Motor. I have some health issues. On the weekend, I'm this superhuman Highland Athlete in a kilt doing the spectacular in front of sometimes hundreds of people.

As in earlier work (Pike, 2007; Sabo, 2004), Ethan's acceptance of risk is also rewarded by the reproduction of an athletic identity he wishes to maintain. To do so requires an embracing of pain, as Ethan also has to contend with some health issues. This exemplifies what Sabo (2004, p64) details as the pain principle, a 'patriarchal cultural belief that pain is inevitable and that the endurance of pain enhances one's character and moral worth'. Ignoring pain also gathers social 
capital with other athletes in awe of the character displayed (Klein, 1995). An example of this phenomenon within the Highland Games risk accepters comes from Patrick (46, M) :

We have a thrower, he was inducted into the Hall of Fame last year. He has leukaemia. Most people with leukaemia kind of give up, he is still here competing and has actually gotten bigger and stronger and because that's our nature. We don't let, we power through injuries and everything and other things like that we tend to look at it like it's just another challenge, it's not an obstacle it's not a problem it's just another challenge that keeps us going mentally and physically.

Here Patrick refers to a well-known athlete within the Masters community. He presents his perspective as that which is indicative of the wider group using the plural noun 'we'. In drawing focus upon the 'nature' of Highland athletes, Patrick also hints at a collective approach to the

pain tolerance and risk profiles of its participants. Battling through physical injuries can therefore be seen in the context of aiding inclusion into the Masters Highland sub-culture, a notion also found amongst younger populations (Donnelly, 2004). Constructing the group as homogenous in this way suggests that existence of a sub-culture that is akin to those found in literature on younger athletes (Hughes and Coakley, 1991; Curry and Strauss, 1994). The normalisation of pain and celebration of those who compete through pain is therefore not unique to young adults involved in sport. But in this sample the risk accepting athletes were in the minority. Most athletes demonstrated what I have detailed as the problem solver perspective.

\section{Problem Solvers}

Unlike the risk accepter who approaches their sport undeterred, the problem solver seeks knowledge and devotes time to complex rehabilitation programmes. This is an example of what Giddens (1991a; 1991b) understands to be a modern understanding of risk, an approach to risk which involves the avoidance of negative outcomes. Interestingly, both the risk accepter and problem solver understand their participation through the binary lens of living versus existing, as exemplified by Heather $(52, \mathrm{~F})$ :

I definitely want to LIVE (her emphasis), and not simply exist. To that end, I do everything possible to ensure that I train and compete injury-free, so I incorporate a lot of self-correction like myofascial release (SMR) and accessories that complement the Highland Games events into a fairly strict regime of power training. On top of that, add Epsom salt soaks at least weekly and professional massage therapy every 3-4 weeks.

Where Heather and Ethan deviate is in their responses to such an understanding. The problem solver strives for the reclamation of control over their ageing bodies, situating ageing as something that can be negotiated by rational decision making. Many problem solvers exhibited an entrepreneurism that will do anything to avoid the negative realities of ageing. This approach relied upon intervention from experts. Sports medicine experts helped athletes understand their physical problems and provided age appropriate changes to warm up routines and preparation strategies. One example comes from Barry $(47, \mathrm{M})$ : 
I was blessed to spend a year training with Darren Borris, a coach who went on to be the conditioning coach for the Atlanta Falcons NFL team. He identified the challenges of a Masters athlete, and my specific weaknesses and created a warm up regime for me.

Sports medicine tends to be reserved 'to a relatively small, elite performer, population' (Safai, \& Malcolm, 2016, p169), yet many of these Highland athletes also have access to such specialists. Problem solvers often had secure occupations and thorough health insurance, allowing access to specialists that might otherwise be prohibitively expensive. Sports medicine covers physicians within sporting fields but also physiotherapists or physical therapists (Theberge, 2007). Alongside these experts, problem solvers also interacted with chiropractors and osteopaths. The inclusion of these alternative experts is not unique to the Highland Games, with Theberge (2008) detailing their use in other sporting fields. Some of these alternative practitioners were reportedly present at Highland Games events within the US. This, however, was not the case at the 2014 World Championships in Inverness. Nevertheless, accessing these practitioners was a quick fix, one that Heather $(52, \mathrm{~F})$ positions as more effective than personal bodywork:

I have an extra vertebra in my lower spine and it tends to keep my hip out of balance, so I've done all sorts of things learning how to manage that, because yesterday when I left the field it felt like it was jammed, if there is a chiropractor on the field that's wonderful because they can fix me right up, but if not, then I've got to do it myself. And so I've spent a great deal of time last night and this morning trying to stretch it, and dislocate it and impinge it and just all of those things which you have to do, I'm feeling pretty good this morning, but it's a tricky business.

Where use of chiropractors and osteopaths was understood as a temporary solution, other experts where called upon to devise strategies to fix the ailing body more permanently. This was a restorative process that would allow for continued participation. It was not for performance enhancement as in the work of Theberge (2007). These specialists were either exercise scientists, who specialised in the biomechanical movements of bodies, or strength and conditioning coaches. These experts brought optimistic narratives that contrasted with the pessimistic views that some athletes perceived of mainstream medical practitioners. The hopes of a continued career were bolstered by these ideas and meant that ageing was reframed as something that could be managed through the right regime completed by a devoted and responsible athlete. Understandings of bodily (dys)function were often disseminated through 'movement screenings', which identified patterns of movement which may lead to pain and injury in the future. This process means the body is understood, calculated and made more manageable- a body that Lupton (2013, p398) describes as 'displayed and made visible'. One problem solver who based his progress on such practices was Matthew $(51, \mathrm{M})$ :

Yes, not long ago touching my toes was challenging for me, I don't, I mean now it's easy, there are still things which are weak but they're better and they have on the functional movement screen I think I was originally 14 and I improved to 16 and what they found with fire fighters, those that score below a 16 a large percentage of them are injured within 2 years so my idea is to not give it up because I don't want to get injured and that's what happens with a lot of the unwise older athletes. 
Matthews approach to understanding the body gives a sense of control. His deriding of nonproblem solvers as 'unwise older athletes' is an explicit nod to responsibilisation discourses that locate those who are not self-reliant as irresponsible. Armed with such knowledge and wisdom, problem solvers could manage their ageing through adherence to age-appropriate programmes. Where professional athletes may be guided through their rehabilitation with an expert present or within a team (Theberge, 2007), many Masters athletes pursued their programmes alone and continuously. Bodily regimes were not for the duration of an injury but became an everyday part of being a Masters athlete. Despite the close monitoring and manipulation of the ageing body, injuries continued to occur. Here Heather $(52, \mathrm{~F})$ explains the limitations of her problem solving approach:

When I say the hip "quit," I need to tell you that there was no apparent injury or slippage, just pain and restricted motion in days to follow. After trying to fix it myself for several months, I went to the orthopaedist last week to learn that all of my cartilage is gone. I have mixed emotions, at this point, as at least I know WHY rehabilitation had become a second full time job!

Heather's quote demonstrates the extent to which problem-solving practices become an everyday essential activity. The problem solver allows ideas of risk to become a defining characteristic of sporting participation.

\section{Discussion}

The risk-accepter: problem solver ideal types capture the differing approaches to risk in the Games, but it should be noted that most athletes were biased towards a problem-solving approach. This suggests that Masters athletes are more disposed to a 'culture of precaution' than a 'culture of risk' (Safai, 2003). The extent to which a problem solving approach was adopted varied. Problem solvers such as Heather, Matthew and Barry spent significant sums of money on expertise in order to inform their preventative measures. This use of sports medicine was akin to elite athletes explored elsewhere (Safai and Malcolm, 2006; Theberge, 2008). Others simply purchased extended health insurance that would financially cover potential injuries. Irrespective of the nature of risk-averting methods, problem solvers framed their efforts in relation to ageing. New training programmes and tailored warm ups were required for the ageing body. Extended insurance was appropriate for a body that felt more fragile and more likely to breakdown. The reflexive approach of the problem solvers represents a late modern risk perception; one that aims to provide insurance to impending threats (Giddens, 1991b). Ageing, like late modernity (Giddens, 1991a), provides a continuous flow of hazards that must be averted through risk management strategies. The use of alternative experts who may not be backed by evidenced based knowledge, is an example of how problem solvers utilise the precautionary principle to hopefully avoid any future hazards.

Problem solvers also understand the limitations of their own knowledge and put trust in 'expert systems' of knowledge (Giddens, 1991a, p18). This lies opposite the risk as adventure approach demonstrated by the risk accepters. Trust is directed internally to the courageous self that will avoid pain and injury. This represents a more traditional approach to risk; one which see's 
potential gain to be achieved through meaningful action (Giddens, 1991b). Understandings of risk and their reactions were diametrically opposed between the risk accepter and problem solver. Yet their underlying rationales were often aligned. The maintenance of an identity was shared between these ideal types. Inclusion in the group was reliant upon participation, so either accepting risks and normalising pain, or continuously solving body problems were required.

Both approaches also resist ageism. This case study adds further support to Phoenix and Smith's (2011) suggestion that resistance to ageism is multidimensional. Both ideal types challenge an ageist discourse that locates physical activity as harmful to older adults (Devereux-Fitzgerald, Powell, Dewhurst, \& French, 2016). To some extent problem solvers inherently accept that physical activity can be harmful, but their approach attempts to negate this reality. Their entrepreneurial approaches are premised on the acceptance of ageing as throwing up potential physical challenges. There is an inherent belief that the ageing body is malleable (Tulle, 2008a) and manageable. The resistance of risk accepters also challenges the biological basis of ageing, with the 'mask of ageing' (Featherstone, \& Hepworth, 1995) used as a tool to avoid disengagement narratives. It is therefore clear that the Masters Highland Games can be a competitive sporting practice which provides the space for resisting the negative social conceptions of getting older. But could it be that both risk accepters and problem solvers unintentionally further denigrate old age? The risk accepter approach degrades old age through adopting approaches associated with youthism (Pfister, \& Lenneis, 2015), whilst problem solvers demean old age through their sustained efforts to avoid it. These sophisticated attempts to delay ageing, in the hope of prolonging sporting participation, unintentionally reproduces a healthism that renders irresponsible those older adults who do not become self-governing. The Masters athletes did not primarily locate participation for health as a rationale for participation, yet their techniques to delay ageing align with the logics of healthism (Crawford, 1980).

This case study therefore demonstrates that some traits identified within younger sporting populations continue into Masters sport. Risk accepters operationalise emotional labour, as in younger populations (Sinden, 2010; Markula, 2015), to reproduce athletic identities. On the other hand, problem solvers rely upon embodied labour to maintain their athletic identities. The everyday nature of problem solving, contextualised by a resistance of biological ageing, is unique to the Masters community. Yet the normalisation of preventative measures is akin to those in elite sport. Whereas elite performers are paid to maximise performance, problem solving Masters athletes fund others to sustain participation. This work has extended a focus on how athletes manage risk to Masters populations. It can be seen to add nuance to a body of literature that is based overwhelmingly on youth and elite populations. Further research should explore other Masters communities to see if a similar approach is found across sports. As this case study is based on a sport dominated by men, it would also be fruitful to explore potential gender differences which may intersect the impact of ageing on risk approaches.

\section{References}

Academy of Medical Sciences. (2009). Rejuvenating ageing research, London: AMS 
Albert, E. (1999). Dealing with Danger: The Normalization of Risk in Cycling. International Review for the Sociology of Sport, 34(2): 157-171.

Baker, J., Fraser-Thomas, J., Dionigi R,, \& Horton A (2010) Sport participation and positive development in older persons. European Review of Aging and Physical Activity, 7(1), 312.

Bale, J. (2006). The place of pain in running. In S., Loland, B., Skirstad, \& I., Waddington. (Eds.). Pain and Injury in Sport. Social and Ethical Analysis. (pp 65-75) Abingdon: Routledge

Beck, U., Giddens, A., \& Lash, S. (1994). Reflexive Modernisation. Cambridge: Polity.

Bernstein, B. (2001). Symbolic control: issues of empirical description of agencies and agents. International Journal of Social Research Methodology, 4(1), 21-33.

Brown, B. J., \& Baker, S. (2013). Responsible Citizens: Individuals, Health and Policy under Neoliberalism. London: Anthem Press.

Brymer, E. (2010). Risk taking in Extreme Sports: A phenomenological perspective. Annals of Leisure Research, 13(1-2), 218-238.

Bunton, R., \& Burrows, R. (1995). Consumption and health in the 'epidemiological'clinic of late modern medicine. In R., Bunton, R., Burrows, \& S., Nettleton. (Eds.). The Sociology of Health Promotion, 206-222. London: Routledge

Charlesworth, H. (2004). Sports-related Injury, Risk and Pain: The Experiences of English Female University Athletes, Unpublished doctoral dissertation, Loughborough University, UK 
Charlesworth, H., \& Young, K. (2006). Injured female athletes: Experiential accounts from England and Canada. In S., Loland, B., Skirstad, \& I., Waddington (Eds.). Pain and Injury in Sport. Social and Ethical Analysis (pp 89-106). Abingdon: Routledge

Connell, R. W. (2005). Masculinities. Cambridge: Polity.

Crawford, R. (1980). Healthism and the medicalization of everyday life. International Journal of Health Services, 10(3), 365-388.

Curry, T. J., \& Strauss, R. H. (1994). A little pain never hurt anybody: A photo-essay on the normalization of sport injuries. Sociology of Sport Journal, 11(2), 195-208.

Dallaire, C., Lemyre, L., Krewski, D., \& Gibbs, L. B. (2012). The gap between knowing and doing: how Canadians understand physical activity as a health risk management strategy. Sociology of Sport Journal 29(3): 325-347.

Dankel, S. J., Loenneke, J. P., \& Loprinzi, P. D. (2017). Health outcomes in relation to physical activity status, overweight/obesity, and history of overweight/obesity: a review of the WATCH paradigm. Sports Medicine 47(6): 1029-1034.

Davies, A., \& James, A. (2016). Geographies of ageing: Social processes and the spatial unevenness of population ageing. London: Routledge.

Devereux-Fitzgerald, A., Powell, R., Dewhurst, A., \& French, D. P. (2016). The acceptability of physical activity interventions to older adults: A systematic review and meta-synthesis. Social Science \& Medicine, 158, 14-23.

Dionigi, R. A. (2002). Resistance and empowerment through leisure: the meaning of competitive sport participation to older adults. Society and Leisure, 25, 2, 303-28

Dionigi, R. A. (2015). Pathways to Masters Sport: Sharing Stories from Sport 'Continuers', 'Rekindlers' and 'Late Bloomers'. In Phoenix, C and Tulle, E. (eds) 
Physical Activity and Sport in Later Life (pp. 54-68). Basingstoke: Palgrave Macmillan UK.

Dionigi, R. A. (2015). Stereotypes of aging: Their effects on the health of older adults. Journal of Geriatrics, 1-9

Donnelly, P. (2004). Sport and risk culture. In K., Young. (Eds.). Sporting bodies, damaged selves: Sociological Studies of Sports-related Injury, (pp 29-57). Bingley: Emerald

Dragoo, J. L., \& Braun, H. J. (2010). The effect of playing surface on injury rate. Sports Medicine, 40(11), 981-990.

Eime, R. M., Harvey, J. T., Charity, M. J., \& Payne, W. R. (2016). Population levels of sport participation: implications for sport policy. BMC Public Health, 16(1), 752.

Estes, C. L., \& Binney, E. A. (1989). The biomedicalization of aging: Dangers and dilemmas. The Gerontologist, 29(5), 587-596.

Featherstone, M. \& Hepworth, M. (1982). `Ageing and Inequality: Consumer Culture and the New Middle Age'. In D., Robbins, C., Caldwell, G., Day, K., Jones, \& H., Rose. (Eds.). Rethinking Social Inequality. (pp. 97-126) Aldershot: Gower

Featherstone, M., \& Hepworth, M. (1995a). The mask of ageing and the postmodern lifecourse. In M. Featherstone, M. Hepworth, \& B. S. Turner (Eds.), The Body: Social Process and Cultural Theory. (pp 371-389). London: Sage

Featherstone, M., \& Hepworth, M. (1995b). 'Images of Positive Aging'. In M. Featherstone, \& A. Wernick (Eds.) Images of Aging, (pp. 29-47). London: Routledge.

Geard, D., Reaburn, P. R., Rebar, A. L., \& Dionigi, R. A. (2017). Masters athletes: Exemplars of successful aging? Journal of Aging and Physical Activity, 25(3), 490-500.

Giddens, A. (1991a). Modernity and Self-Identity. Cambridge: Polity Press 
Giddens, A. (1991b). The Consequences of Modernity. Cambridge: Polity Press

Giddens, A. (1992). The Transformations of Intimacy. Cambridge: Polity Press

Giddens, A. (1999). Runaway World, How Globalisation Is Reshaping Our Lives. London: Profile Books

Gullette, M. M. (1997). Declining to decline: Cultural combat and the politics of the midlife. Virginia: University of Virginia Press.

Horne, J., \& Jary, D. (2004). Anthony Giddens: structuration theory, and sport and leisure. In R., Giulianotti (Eds.). Sport and modern social theorists (pp. 129-144). Palgrave Macmillan, London.

Hughes, R., \& Coakley, J. (1991). Positive deviance among athletes: The implications of over conformity to the sport ethic. Sociology of Sport Journal, 8(4), 307-325.

Jarvie, G. (2005). The North American Émigré, Highland Games, and social capital in international communities. In C. Ray. (Eds.). Transatlantic Scots, (pp 198-214) Alabama: University of Alabama Press

Klein, A. (1995). Life's too short to die small: steroid use among male bodybuilders. In D., Sabo, \& F., Gordon, (Eds.). Men's health and Illness: Gender, power and the body. London: Sage

Loland S, Skirstad, B. \& Waddington, I. (2006). Pain and Injury in Sport. Social and Ethical Analysis. Abindgon, Routledge

Liston, K., McDowell, M., Malcolm, D., Scott-Bell, A., \& Waddington, I. (2018). On being 'head strong': The pain zone and concussion in non-elite rugby union. International Review for the Sociology of Sport, 53(6), 668-684 
Liston, K., Reacher, D., Smith, A., \& Waddington, I. (2006). Managing pain and injury in nonelite rugby union and rugby league: A case study of players at a British university. Sport in Society, 9(3), 388-402

Lupton, D. (1995). The imperative of health: Public health and the regulated body. London: Sage.

Lupton, D. (2013). Risk. London: Routledge.

Malcolm, D., \& Pullen, E. (2018). 'Everything I enjoy doing I just couldn’t do': Biographical disruption for sport-related injury. Health, doi: 10.1177/1363459318800142

Markula, P. (2015). (Im)Mobile bodies: Contemporary semi-professional dancers' experiences with injuries. International Review for the Sociology of Sport, 50(7), 840-864

Mayer, J., \& Thiel, A. (2018). Presenteeism in the elite sports workplace: The willingness to compete hurt among German elite handball and track and field athletes. International Review for the Sociology of Sport, 53(1), 49-68.

McKay, J., Messner, M. A., \& Sabo D. (2000). Masculinities, Gender Relations, and Sport. Thousand Oaks: Sage publications.

Messner, M. A. (1992). Power at play: Sports and the problem of masculinity. Boston: Beacon Press.

Messner, M. A., \& Sabo, D. (1990). Sport, men, and the gender order: Critical feminist perspectives. Champaign, IL: Human Kinetics

Monaghan, L. F. (2001). Bodybuilding, Drugs and Risk. London: Routledge

Murphy, D. F., Connolly, D. A. J., \& Beynnon, B. D. (2003). Risk factors for lower extremity injury: a review of the literature. British Journal of Sports Medicine, 37(1), 13-29. 
Nixon, H. L. (1992). A social network analysis of influences on athletes to play with pain and injuries. Journal of Sport and Social issues, 16(2), 127-135.

Nixon, H. L. (1994). Coaches' views of risk, pain, and injury in sport, with special reference to gender differences. Sociology of Sport Journal, 11(1), 79-87.

Nixon, H. L. (1996). Explaining pain and injury attitudes and experiences in sport in terms of gender, race, and sports status factors. Journal of Sport and Social Issues, 20(1), 33-44.

Palmer, V. J., Tulle, E., \& Bowness, J. (2018). Physical Activity and the Ageing Body. In (S.R. Nyman et al., (Eds.) The Palgrave Handbook of Ageing and Physical Activity Promotion (pp. 531-549). Cham, Switzerland: Palgrave Macmillan

Pfister, G. (2012). It is never too late to win-sporting activities and performances of ageing women. Sport in Society, 15(3), 369-384.

Pfister, G., \& Lenneis, V. (2015). Ageing women still play games:(Auto) ethnographic research in a fitness intervention. In E. Tulle, \& C. Phoenix, (Eds.). Physical activity and sport in later life. (pp. 149-160). Palgrave Macmillan, London.

Phoenix, C., \& Smith, B. (2011) Telling a (good?) counterstory of aging: Natural bodybuilding meets the narrative of decline. Journals of Gerontology Series B: Psychological Sciences and Social Sciences, 66(5), 628-639.

Pike, E. C. (2005). 'Doctors Just Say "Rest and Take Ibuprofen”" A Critical Examination of the Role of 'Non-Orthodox 'Health Care in Women's Sport. International Review for the Sociology of Sport, 40(2), 201-219.

Pike, E. C. (2007). Revisiting the Physical Activity, Sexual Health, Teenage Identity Construction Nexus'. International Review for the Sociology of Sport, 42(3), 309-319. 
Pike, E. C. (2011a). Aquatic antiques: Swimming off this mortal coil? International Review for the Sociology of Sport, 47(4), 492-510.

Pike, E. C. (2011b). The active aging agenda, old folk devils and a new moral panic. Sociology of Sport Journal, 28(2), 209-225.

Powell, J.L., \& Biggs, S. (2003). Foucauldian gerontology: A methodology for understanding aging. Electronic Journal of Sociology, 7(2), 1-14.

Pullen, E., \& Malcolm, D. (2018). Assessing the side effects of the 'exercise pill': the paradox of physical activity health promotion. Qualitative Research in Sport, Exercise and Health, $10(4), 493-504$.

Roderick, M., Waddington, I., \& Parker, G. (2000) Playing Hurt. Managing injuries in English professional football. International Review for the Sociology of Sport, 35(2), 165-180.

Rose, N. (2007). The Politics of Life Itself: Biomedicine, Power and Subjectivity in the TwentyFirst Century. Princeton, NJ: Princeton University Press

Rowe, J. W., \& Kahn, R. L. (1987) Human aging: usual and successful. Science, 237(4811), 143149.

Sabo, D. (2004). The politics of sports injury: Hierarchy, power, and the pain principle. In K., Young. (Eds.). Sporting bodies, damaged selves: Sociological studies of sports-related injury, (pp 59-79). Boston: Elsevier

Safai, P. (2003). Healing the body in the "culture of risk": Examining the negotiation of treatment between sport medicine clinicians and injured athletes in Canadian intercollegiate sport. Sociology of Sport Journal, 20(2), 127-146.

Safai, P., \& Malcolm, D. (2016). 'Sport, Health, Medicine'. In B. Houlihan, \& D. Malcolm (Eds.). Sport and Society. London: Sage 
Sinden, J. L. (2010). The normalization of emotion and the disregard of health problems in elite amateur sport. Journal of Clinical Sport Psychology, 4(3), 241-256.

Smith, J. A., Flowers, P., \& Larkin, M. (2009). Phenomenological analysis. Theory method \& research. London: Sage

Theberge, N. (2007). 'It's not about health, it's about performance': Sport medicine, health, and the culture of risk in Canadian sport. In P., Vertinsky, \& J., Hargreaves. (Eds.). Physical Culture, Power, and the Body. (pp. 190-208). London: Routledge.

Theberge, N. (2008). The integration of chiropractors into healthcare teams: a case study from sport medicine. Sociology of Health \& Illness, 30(1), 19-34.

Thompson, P. (1992). 'I don't feel old': Subjective ageing and the search for meaning in later life. Ageing and Society, 12(1), 23-47.

Tulle, E. (2008a). Ageing, the body and social change: Running in later life. Basingstoke: Palgrave Macmillan.

Tulle, E. (2008b). Acting your age? Sports science and the ageing body. Journal of Aging Studies, 22(4), 340-347.

Waldron, J., \& Krane, V. (2005). Whatever it Takes: Health Compromising Behaviors in Female Athletes. Quest, 57(3), 315-329

Weber, M. (1978). Economy and society: An outline of interpretive sociology. California: University of California Press.

Young, K. (1993). Violence, risk, and liability in male sports culture. Sociology of Sport Journal, 10(4), 373-396.

Young, K. (2004). Sporting bodies, damaged selves: Sociological studies of sports-related injury. Boston: Elsevier 
Young, K., \& White, P. (1995). Sport, physical danger, and injury: The experiences of elite women athletes. Journal of Sport and Social Issues, 19(1), 45-61.

Young, K., \& White, P. (2000). Researching sports injury: Reconstructing dangerous masculinities. In J., McKay, M., Messner, \& D. Sabo (Eds.). Masculinities, gender Relations and Sport (pp. 108-126). Thousand Oaks, CA: Sage

Young, K., White, P., \& McTeer, W. (1994). Body talk: Male athletes reflect on sport, injury, and pain. Sociology of Sport Journal, 11(2), 175-194. 